\title{
EROSION, TRANSPORTATION AND THE NATURE OF THE MARIA
}

\author{
T. GOLD \\ Cornell University, Ithaca, U.S.A.
}

\begin{abstract}
Rock dust appears to have been redistributed over the Moon by effects other than impact explosions. A core sample on Apollo 12 showed sharp and distinctive layers and was clearly unmixed. Surface transportation processes that deposit the dust very gently must have been at work. Orbiter pictures confirm that such surface creep has taken place on a very large scale.

The seismic evidence makes clear that there is no continuous sheet of bedrock at a shallow depth in the vicinity of the Apollo 12 site. A deep deposit of powder would match the seismic properties observed. Mascons require for their explanation a surface transportation process that tends to fill in the large impact basins after their formation.

Surface transportation of lunar dust has been demonstrated in the laboratory to occur most readily as a result of electrostatic forces produced by electron bombardment in the energy range of a few hundred volts. Such bombardment happens on the Moon predominantly when it is in the magnetic tail of the Earth, and this may be the reason why mare ground is so remarkably dominant on the hemispere facing the Earth.
\end{abstract}

There is much evidence that erosion and transportation of material over the surface has taken place on the Moon on a substantial scale. There has been very little discussion of the obvious dilemma "Where is all the eroded material now?". Many of the craters in the uplands have been degraded until they have only a small fraction of the height they must once have had were they to have looked like the younger craters do now. Explosive events could not have generated their present shapes. The amount of material apparently removed from all the overlapping highland craters appears to correspond to more than $1 \mathrm{~km}$ of depth averaged over the Moon. Some authors have suggested that all this material has left the Moon altogether, being blasted into space by further impacts. This explanation leads to serious difficulties. Either the infalling stuff removes more from the Moon than the mass falling in, which seems mechanically very unlikely and leads to difficulties for forming the Moon in the first place, or, if less is removed than brought in, the features ought to adopt a generally 'snowed over' appearance, which is certainly not the case.

Where steep mountains meet the plain, the junction line is usually abrupt and there is no indication that all the missing material can be hidden in that vicinity. Some talus slopes exist perhaps on the moon, but certainly they are not a common feature. The only places that can accommodate the large amount of missing material are the surfaces of the maria and the flat interiors of old craters. It was this argument that provided the first reason for suspecting large amounts of finely divided material to cover the mare surfaces (Gold, 1955).

The arguments that surface transportation has taken place on a large scale on th Moon have been greatly strengthened by all the recent evidence. The Moon is indeed covered almost everywhere with a fine powder which could have suffered surface transportation, and not with solid rock which would for the most part be immobile. The depth of this deposit of fine powder is unknown, and while no doubt there will be 


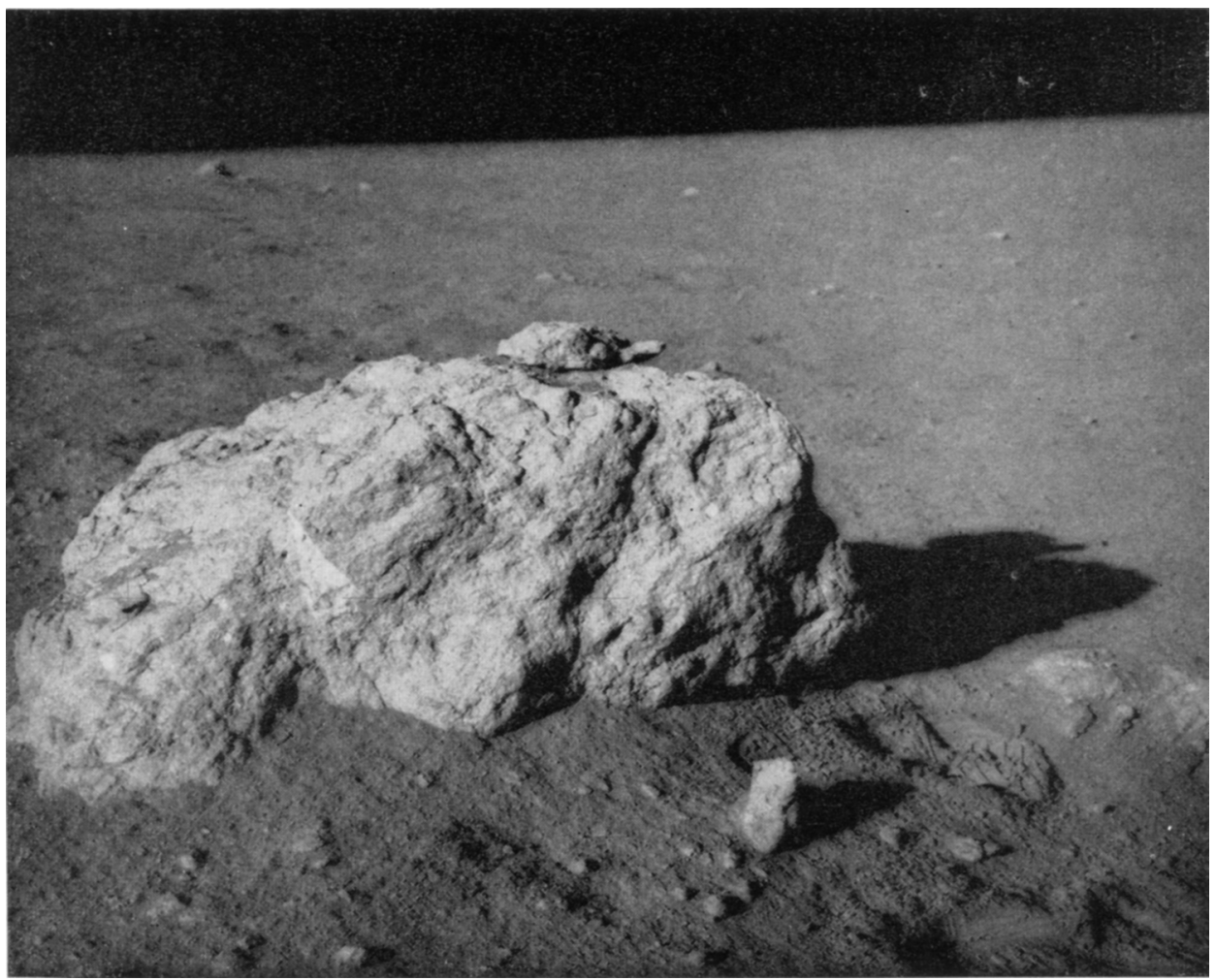

Fig. 1. Rock on the lunar surface, near the Apollo 14 landing site, photographed by the astronauts.

changes of compaction with depth, no one has seen clear evidence of large areas of bedrock anywhere.

On a small scale a surface creep phenomenon must clearly have taken place so that all the many stones scattered over the surface can be neatly imbedded without being snowed over (Figure 1). The random scattering of soil by secondaries from meteorite impacts could not achieve this, but would indeed generate the snowed over appearance. Instead, the rocks are for the most part very clean down to a sharp junction line with the soil, and their surrounds do not show any of the impact scars generated when they were tossed to their present positions. A surface creep phenomenon must be active that is fast enough to achieve this and indeed to counteract the scattering effect of the meteorites.

Plowing over by meteorite impact has been thought of by many authors as being the major surface activity. It has been estimated, for example, that the ground has been plowed over a hundred times to a depth of $40 \mathrm{~cm}$ in the lifetime of the mare surface (Shoemaker et al., 1970).

The evidence of the core tube on Apollo 12 makes clear that the ground at that site 
has not even been plowed over once to a depth of $40 \mathrm{~cm}$. There is clear evidence that the core has striations in height noticeable in optical properties (TLSPET, 1970), in differences of the size distribution of the grains (Gold et al., 1971) and in chemical differences. Anders et al. (1971) has found for example, an increase in some trace elements by a factor as large as $10^{5}$ in one layer of the core. This can only be understood by supposing that the surface has been added to at a rate that exceeds the plowing by meteorites. If one supposed a plowing rate to $40 \mathrm{~cm}$ depth of once in 40 million yr, one thus requires a deposition rate faster than $1 \mathrm{~cm}$ per million $\mathrm{yr}$. The rate required to fill the mare basins in 4 billion yr would be $\sim 1 \mathrm{~cm}$ in $10000 \mathrm{yr}$; however, it seems likely that both infall and transportation were occurring at a much faster rate in earlier epochs.

Mare surface in general is clearly not saturation bombarded since the crater density is regionally quite variable and in general less than in the highlands. This can be understood again as a sign that a deposition process lays down material faster in the mare regions than the plowing by meteorites. Ronca (1971) has studied such regional differences and has mapped them.

The compositional differences between soil and rocks in the same region make clear that the soil is not local bedrock ground up with the rocks being pieces of that same bedrock. This would have been the expected situation if bedrock existed at a shallow depth and if the soil were merely the consequence of its local pulverization.

If instead the soil has suffered some surface creep over big distances, while the rocks are pieces thrown out from major craters and originally represent material at a greater depth, then such compositional differences can indeed be expected.

Lunar Orbiter and Apollo orbital photography show classes of features (Figure 2) on the Moon in fine detail whose origin must be sought in surface transportation mechanisms. Outstanding among those are the 'shoulders' at the junctions of old mountains with flat mare surface. The shoulders are characterized by the following features: at the junction line the ground rises with the steepest gradient that occurs in the entire region. Over distances of some tens or hundreds of meters the gradient flattens, with the level then being some meters or tens of meters above the mare surface. This flattened gradient then meets up in another contact line with the steeper slope of the old mountains (Figure 3).

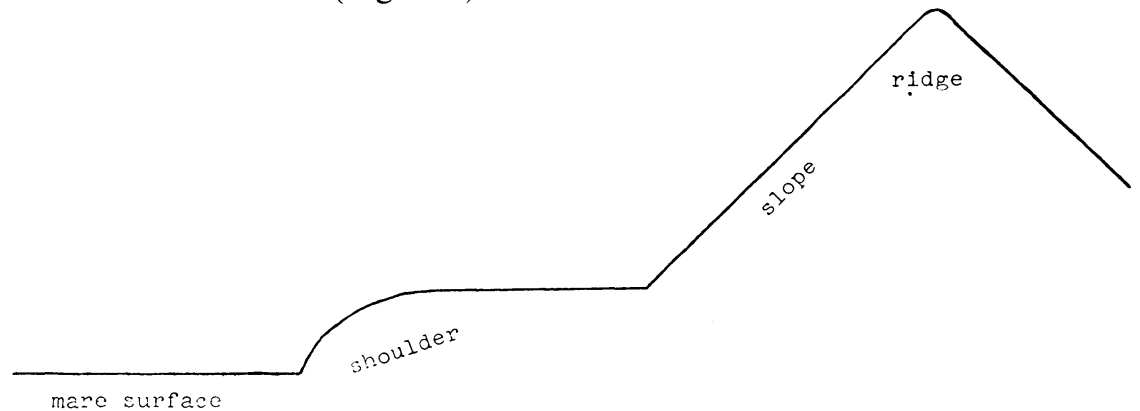

Fig. 2. Illustration of the classes of features studied on Lunar Orbiter photographs. 


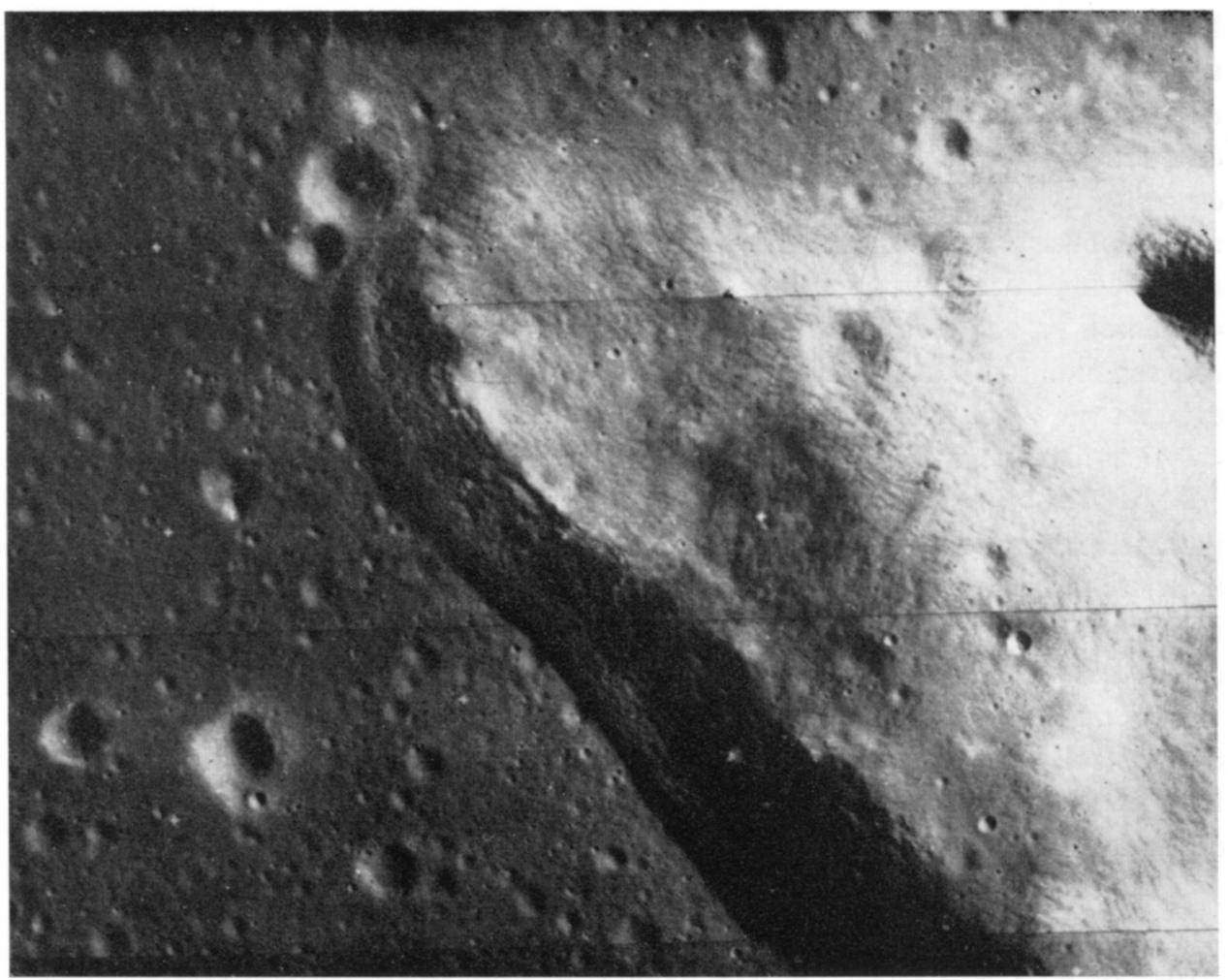

Fig. 3. Lunar Orbiter photograph showing the abrupt junction line where a mountain meets the plain.

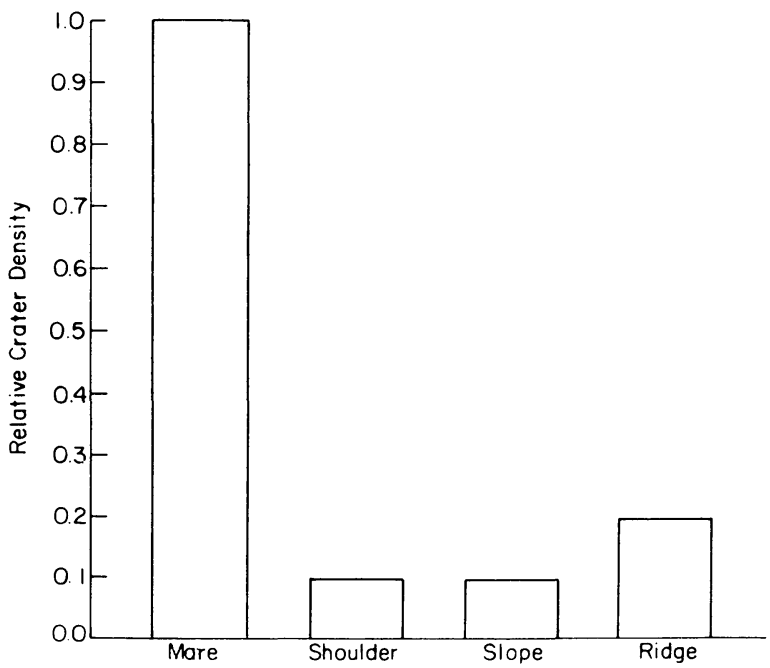

Fig. 4. Average relative crater densities on mountain slopes, shoulders and nearby mare ground, based on Lunar Orbiter photographs. 

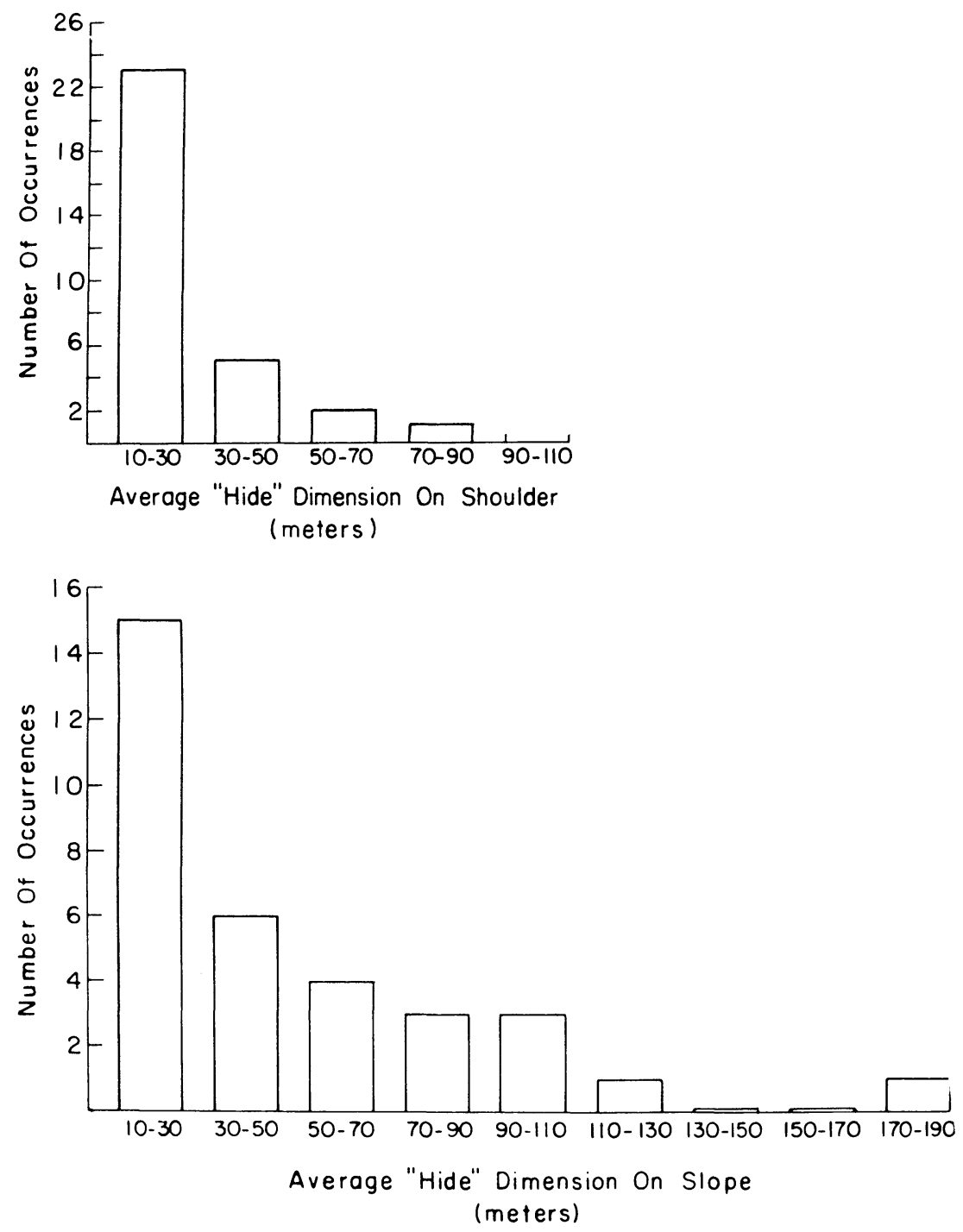

Fig. 5. Histograms of average 'hide' dimensions on mountain slopes and shoulders, based on Lunar Orbiter photographs.

We have investigated more than twenty regions where such shapes are seen and have found that they are quite generally associated with other observable quantities. It is generally true that the crater density in the shoulder is lower than that in the neighboring ground. Also, quite generally, the crisscross pattern seen on most lunar steep slopes ('elephant hide pattern') is usually very pronounced on the old mountain slope and is clearly visible but on a much smaller scale on the shoulders (Figures 4 and 5). This pattern is of course absent on the mare surface. Figures 6 and 7 show features of this kind. 


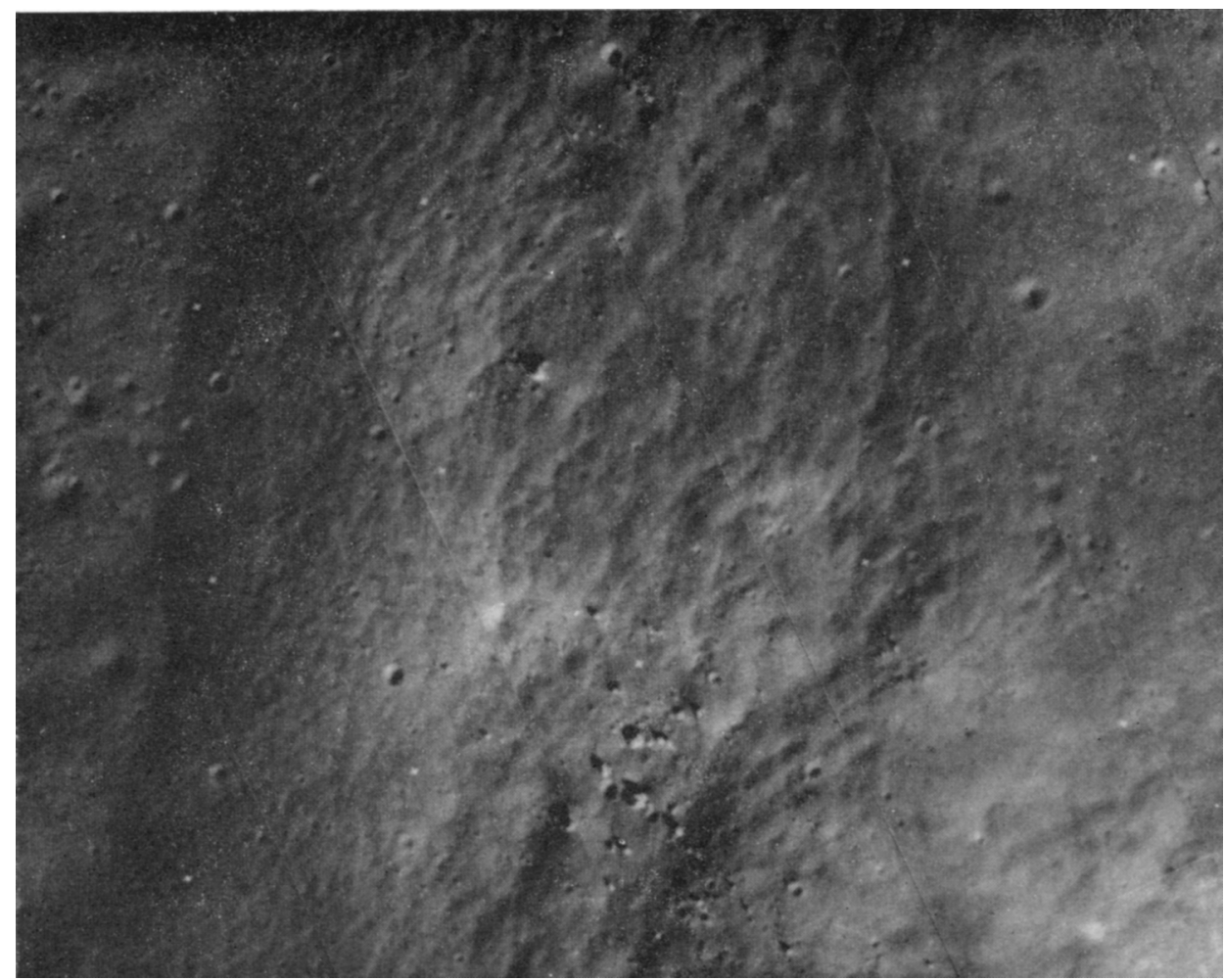

Fig. 6. Lunar Orbiter photograph showing elephant hide patterns on mountain shoulders and slopes.

The judgment that the mountains in these cases are old and heavily eroded stems from many detailed observations. Pieces of arcs are presumably the remains of old craters that have for the most part disappeared. Most of the mountains involved must have been considerably higher when they were thrown up as parts of craters.

Observations on the shoulders make the following points abundantly clear: the material forming the shoulders has come there as a consequence of a surface transportation mechanism. One cannot conceive of any physical process of a general slumping of the shape, nor can one think of lava having poured out into this shape so uniformly along hundreds of miles of old ridges. The relation with the erosion surface patterns strengthens this conclusion. It is further clear that the shoulders have reached their present configuration later than the final shaping of the mare surface. There are many occasions where partly overlapping craters allow a relative chronology to be established. Figure 8 shows such a crater in the flat mare ground partially filled with shoulder material. The nature of the transportation mechanism which has to have been active on quite a large scale is not yet clear. I will discuss a possible mechanism later, and I consider this the outstanding problem for the understanding of the nature of the lunar surface. 


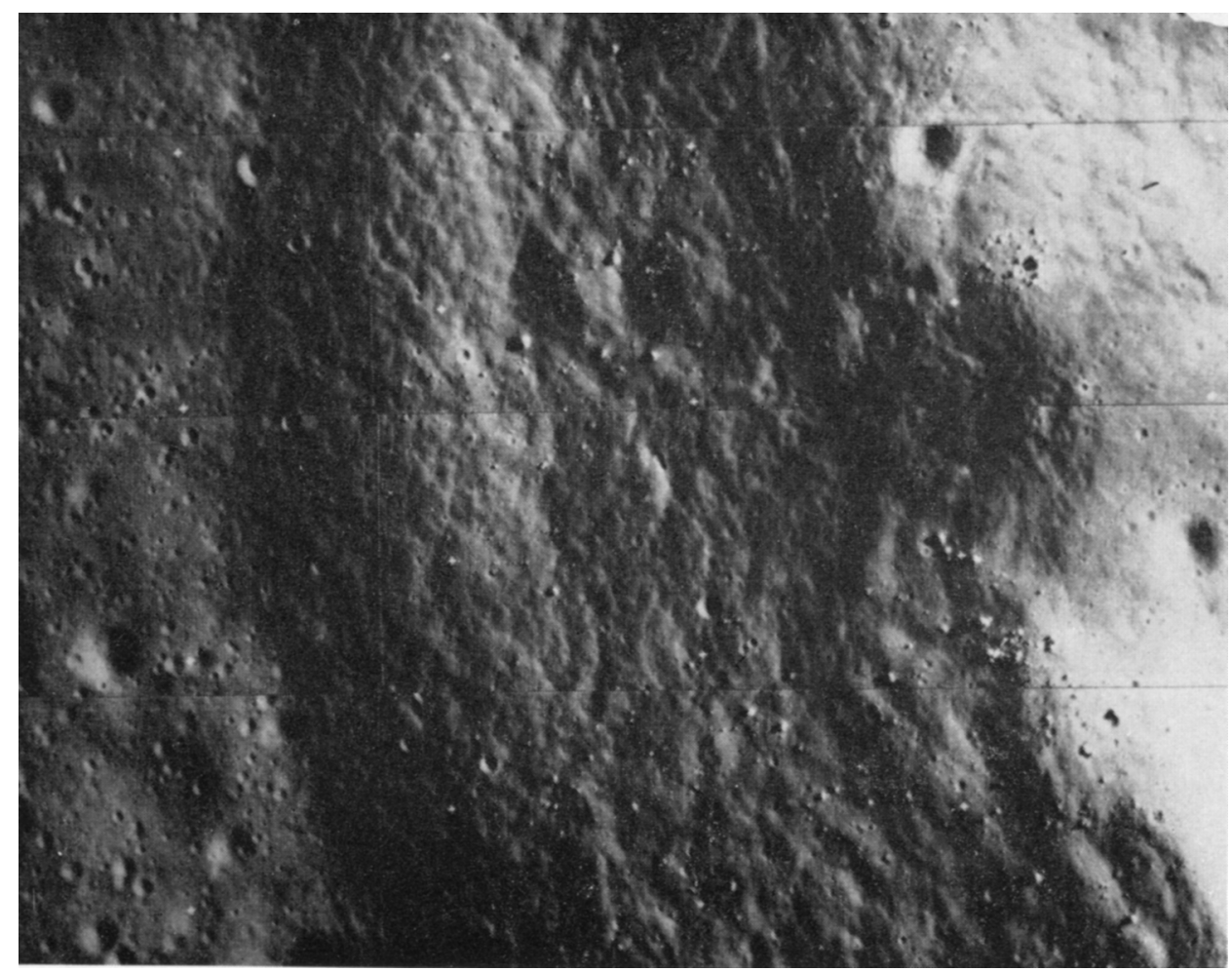

Fig. 7. Lunar Orbiter photograph showing elephant hide patterns on mountain shoulders and slopes.

When we have such clear evidence that the lunar soil has been transported on this scale, we may wonder whether the next larger scale phenomenon, namely the filling of the mare basins, did not occur in a similar manner. Two lines of evidence favor this.

The transmission of seismic signals over distances of tens or hundreds of kilometers on the Moon occurs in a manner totally different from the terrestrial case. The seismic evidence cannot be understood except with an absence of widespread bedrock at a shallow depth and instead the presence of a medium of slower sonic velocity over an interval of several kilometers of depth. Lunar soil gradually compacted with depth will account very well for the whole range of seismic phenomena seen (Ronca, 1971).

Mascons (Gold and Soter, 1970) as distributed positive gravity anomalies covering the floors of most large circular mare basins would be the direct consequence of a cold accreted moon suffering large scale surface transportation. An impact large enough to make a mare basin would leave in the first place a concave basin of fully compacted material, while previously the accumulated material subjected to small scale impacts would have been porous down to a depth of as much as $50 \mathrm{~km}$. Such a basin, now made of denser material, must adjust itself hydrostatically immediately 


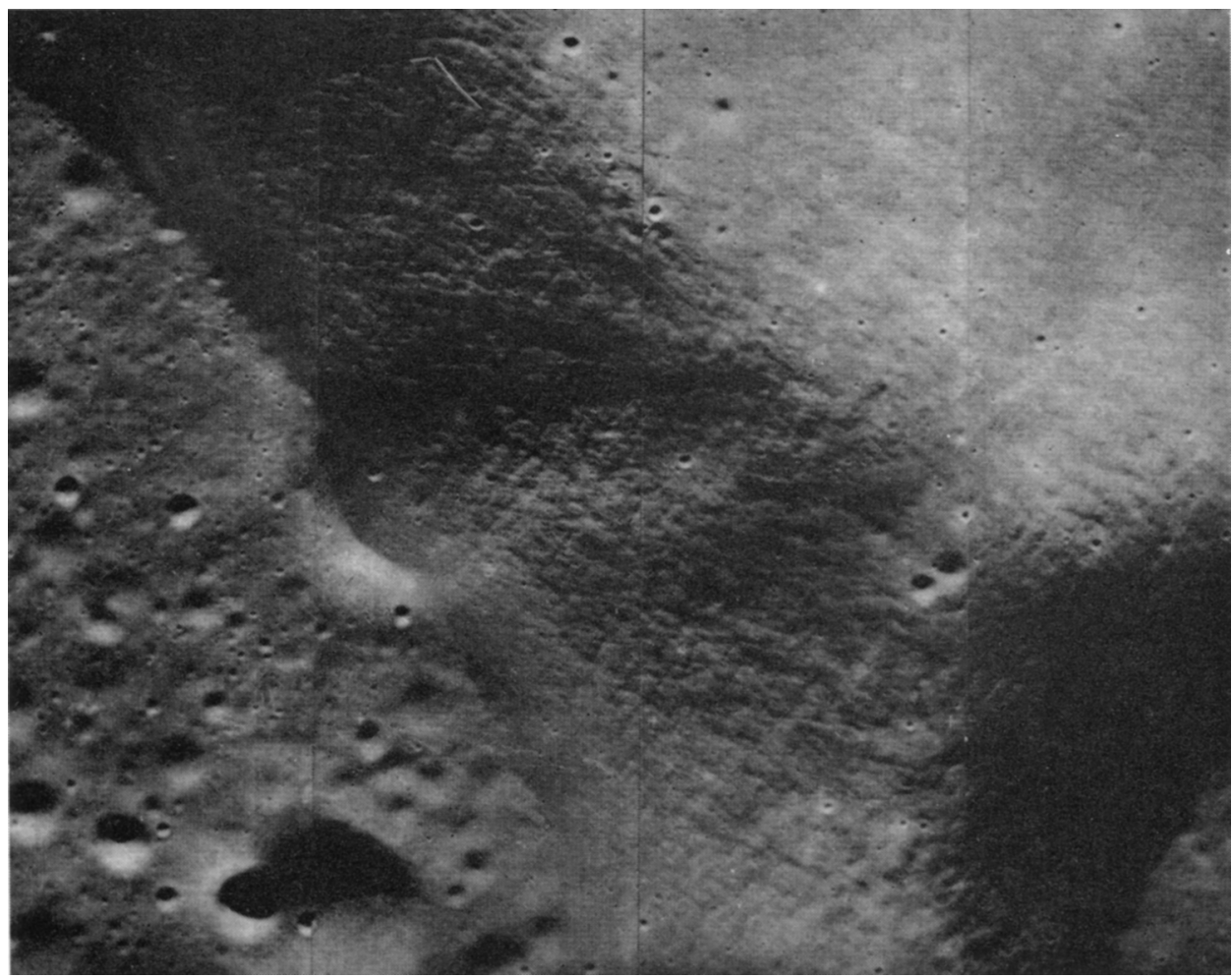

Fig. 8. Lunar Orbiter photograph of a crater in the flat mare ground partially filled with shoulder material.

after the impact, since the strength of no rock can be enough to maintain so large a departure from equilibrium. The floor will thus immediately be forced up to the vicinity of equilibrium, but since the material is denser there than in the surroundings, the equilibrium level will be below the surrounding plain. If porosity was crushed out over a depth of $50 \mathrm{~km}$ an equilibrium level $4 \mathrm{~km}$ lower would be entirely reasonable.

At this stage it can be shown that to a first order there would be no free air gravity anomaly. Since the basin is lower than the surrounds, surface transportation could cause it to be filled, and when as much as 1 or $2 \mathrm{~km}$ has accumulated, a positive gravity anomaly of the observed strength will result. In this case, since the underlying rock can be largely cold (except for a comparatively thin skin of heating and melting caused by the impact) there is no problem of later upholding the extra burden. In theories where this extra burden is due to lava having come up from underneath it is not at all easy to understand how the rock from which it has come can be strong enough to support the imbalance.

I have been concerned for many years now with the problem of discovering the most likely surface transportation mechanism. Although some shapes are suggestive of wind erosion and perhaps a very temporary atmosphere, possibly as a consequence 


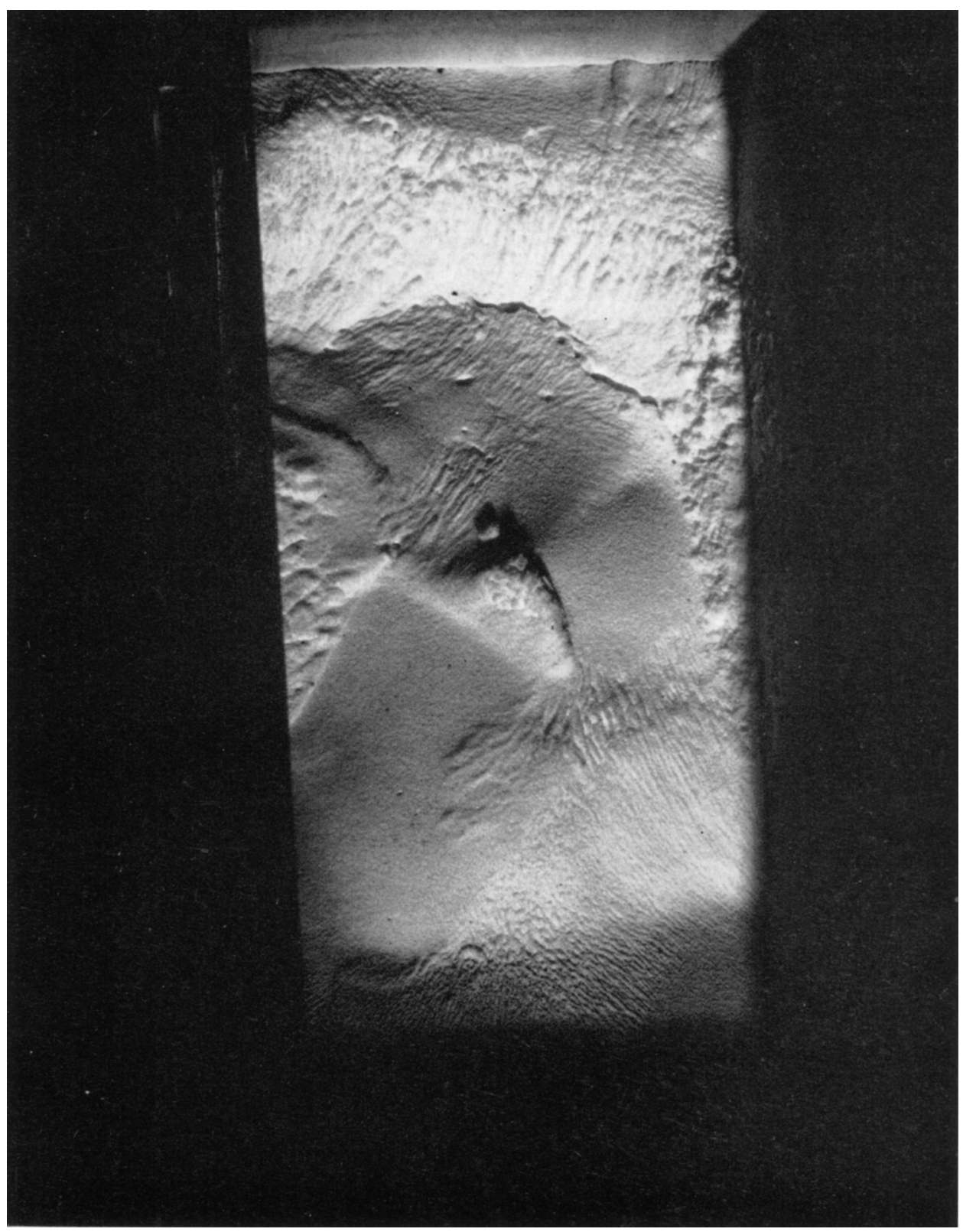

Fig. 9. Surface configuration of an insulating powder $\left(\mathrm{Al}_{2} \mathrm{O}_{3}\right)$ after being exposed to an electron beam of $\sim 500 \mathrm{~V}$ energy. The actual surface area seen on the picture is $6 \times 12 \mathrm{~cm}$. 
of a large impact, many erosion features such as the shoulders can clearly not be accounted for in that way. Equally seismicity cannot be held responsible. Direct solar radiation pressure is also insufficient and also the corresponding latitute dependence is not seen. Electrostatic effects have thus always seemed the most likely.

Among the many electrostatic effects that I have considered and experimentally investigated, there is one that is quite outstanding in its efficacy. It is an effect related to the secondary electron emission characteristics of the material in the presence of electron bombardment. If the primary bombarding electrons come in with an energy in the vicinity of that for which an equal number of secondaries is produced, then the charging of the surface becomes locally quite unstable. For one spot the secondary emission ratio may be slightly more than unity, and it therefore races to become positive until no other surface can receive the secondary electrons and they fall back upon it. Another spot being slightly below the unity value becomes negative until the energy of the incoming electrons is insufficient for them to reach it. Areas are thus driven apart in potential by as much as the energy of the incoming electron beam, and that, for unity in the secondary emission ratio, is of the general order of a few hundred volts for most materials. If neighboring grains a few microns apart develop differences

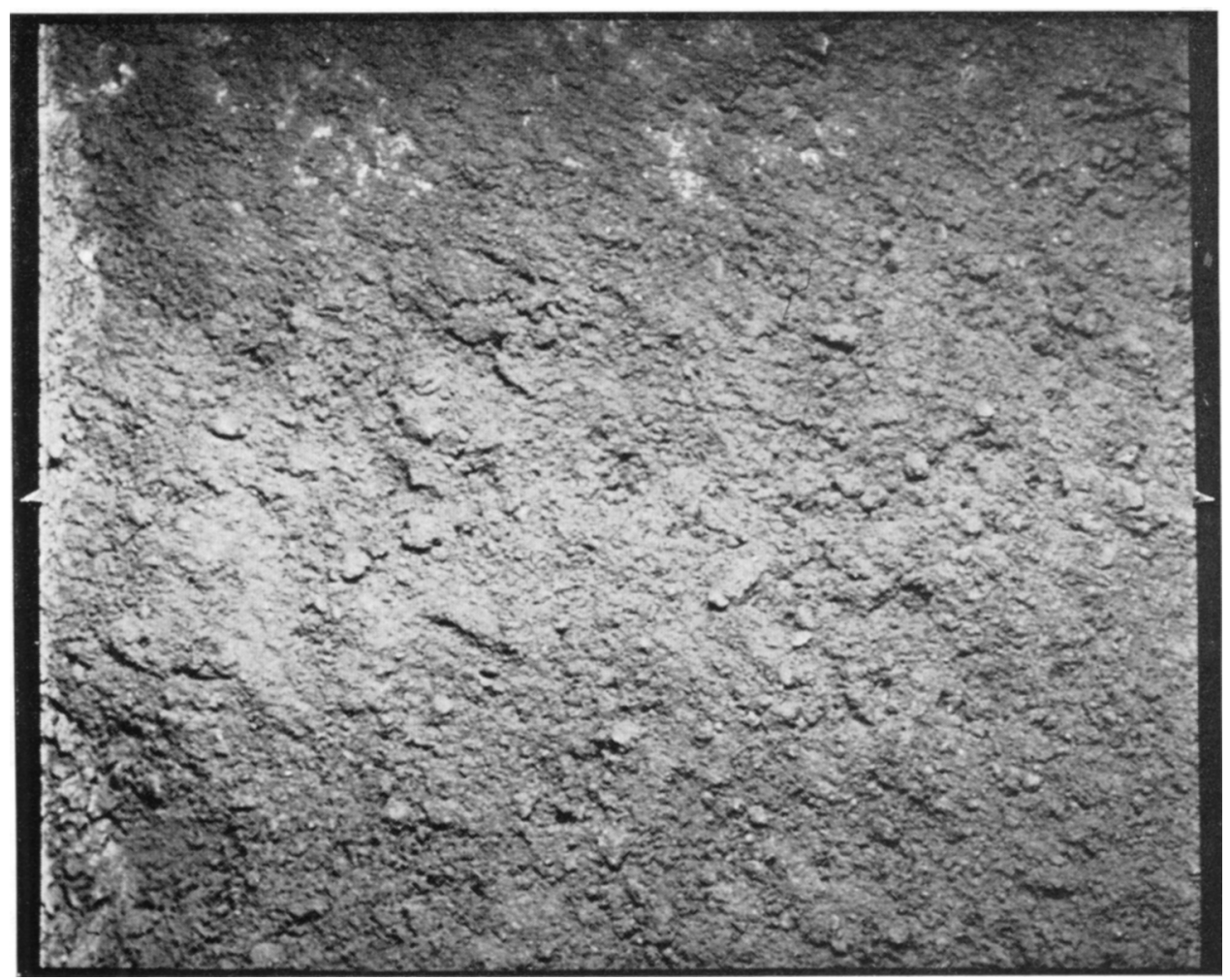

Fig. 10. Single frame print of an Apollo 14 close-up stereo photograph of the lunar surface, showing parallel lines of grooves. The area shown here is $8.3 \times 7.6 \mathrm{~cm}$. 


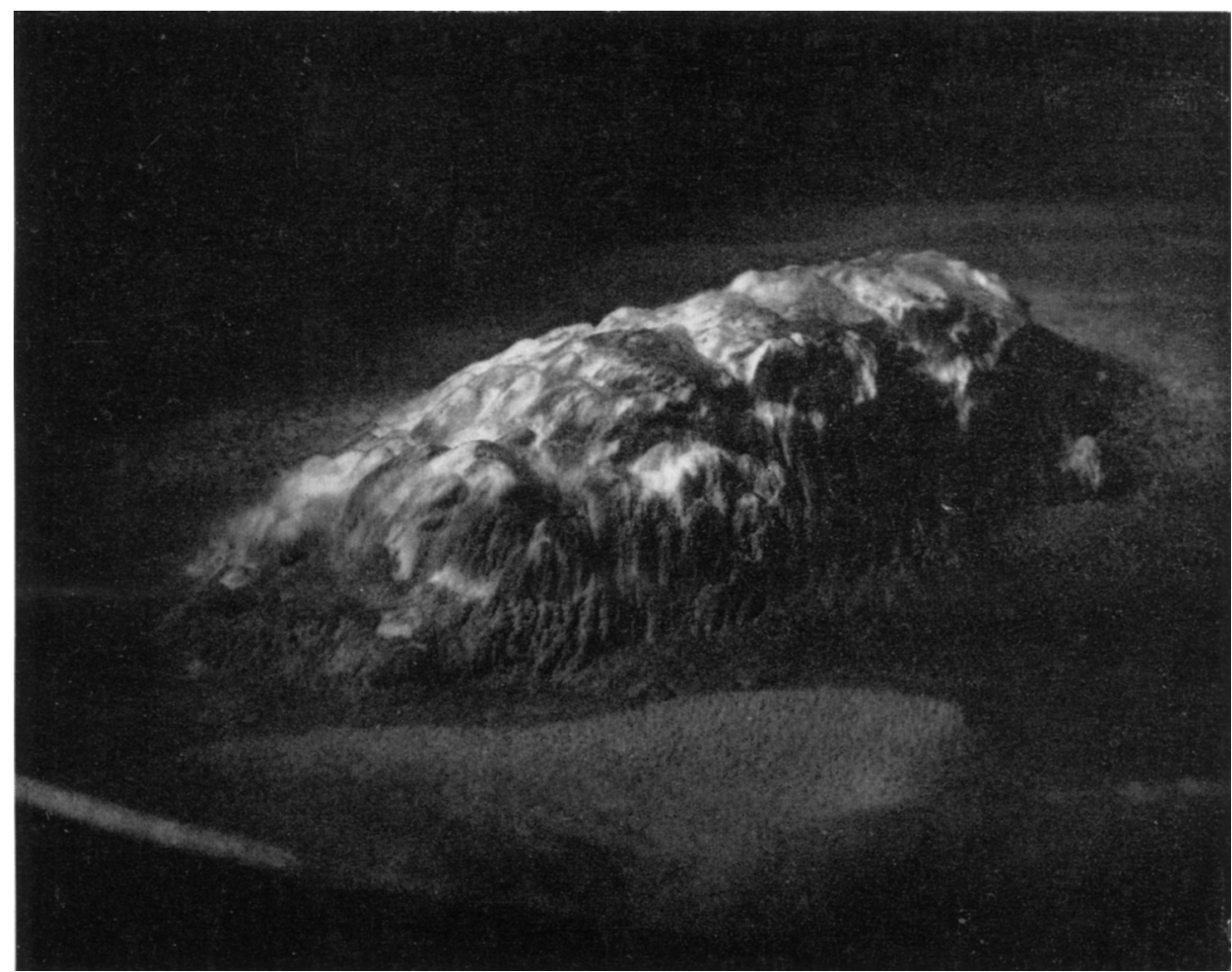

Fig. 11. Configuration of a small pile of insulating rock powder on the top of the flat surface of a chemically different rock powder after electron bombardment in a laboratory vacuum system. (The length of the pile is approximately $6 \mathrm{~cm}$.).

of potential of several hundred volts the electric fields are in the range of millions of volts per centimeter and the forces are then amply sufficient to dislodge and move the grains. This is the effect we have recently investigated extensively in the laboratory and we have observed not only very rapid transportation of grains over the surface but also the development of very particular shapes and features in the surfaces so treated. Parallel lines of grooves and ridges on a millimeter scale are a particularly common type of shape that is so produced. We have seen a remarkable pattern of a similar nature in one of the close-up stereo photographs brought back from the Moon by Apollo 14 (Figures 9 and 10).

Another phenomenon observed in the laboratory is that it is common for the junction line between different materials to remain sharp, and while the junction line itself can move extensively, no mixture of materials is produced. In those cases one material flows over the other retaining a sharp front. This is a phenomenon on a smaller scale but quite reminiscent of the shoulder phenomenon we have described (Figures 11 and 12).

If electrostatic transportation has played a major part in forming the Moon's 


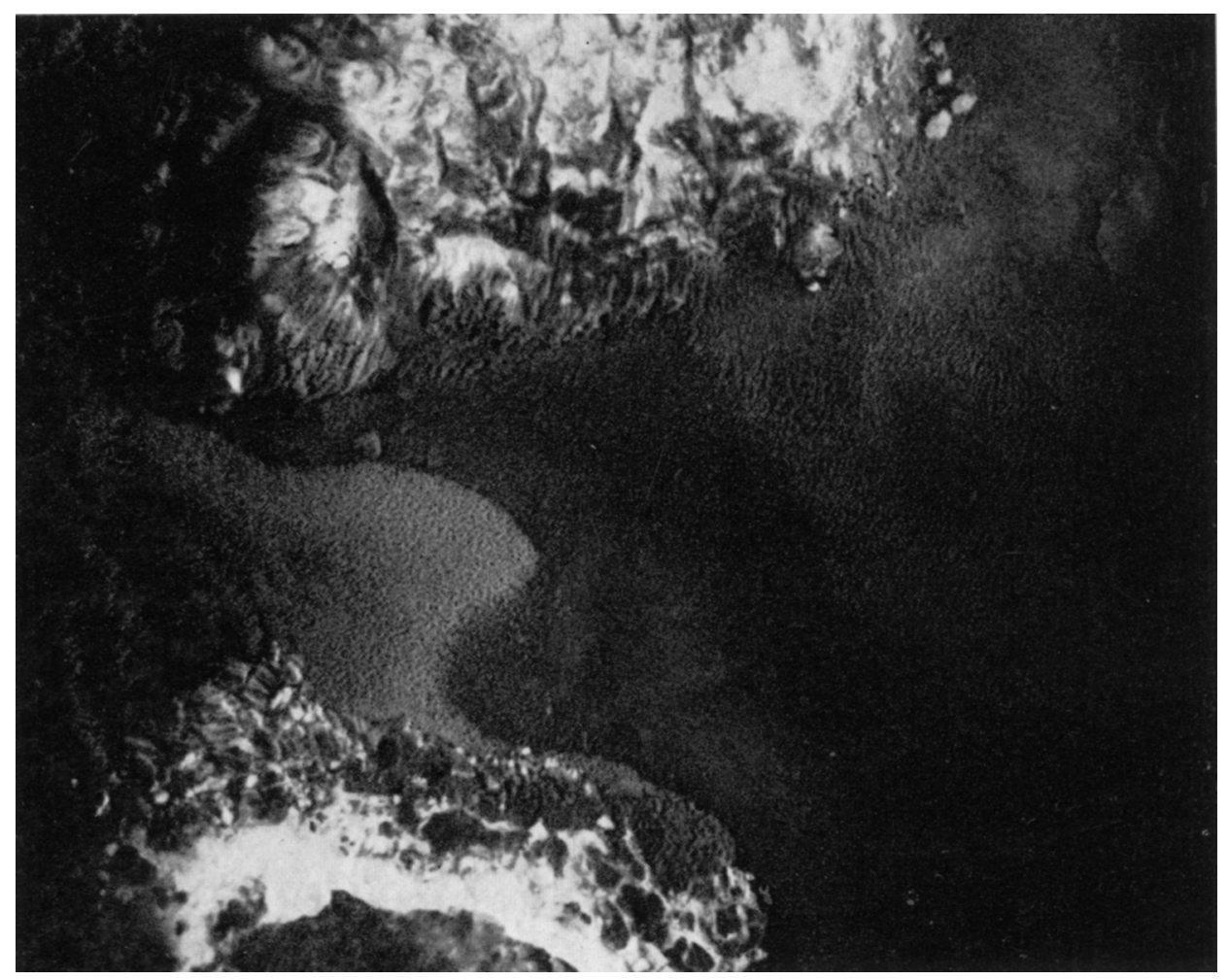

Fig. 12. Junction line formed between different materials subjected to electron bombardment in a laboratory vacuum system. The picture shows an area of approximately $4 \times 6 \mathrm{~cm}$.

surface then the difference in the appearance between the front and the back of the Moon can be understood. Electrons in the range of energy of a few hundred volts do not occur very often in the free solar wind. There the electrons are merely transported along with the protons at the solar wind speeds, and this corresponds to very low electron energies. In the magnetic tail of the Earth a different phenomenon takes place. Through the process of magnetoturbulence, suffered by the solar wind as it strikes the magnetosphere, some energy sharing between electrons and protons takes place, and electron energies are thus increased into the range of several hundreds of volts. We believe that this results in electrons in this energy range being able to hit the near side of the Moon but not the far side. Since the Moon is within the magnetic tail of the Earth for approximately four days each month, this may be a large effect. In the past when the Moon's orbit was undoubtedly much smaller, the effect may have been much larger still.

Thus, if electrostatic transportation is a major phenomenon, big basins on the front side of the Moon may have gradually filled in, while similar basins on the back side would merely be subject to further cratering but to much less filling. So long as we have no detailed knowledge of levels on the Moon, we cannot discover such basins 
when they are not filled. An examination of gravity anomalies should of course then show the mascons to be weaker or absent on the back.

\section{Acknowledgements}

The analysis of Orbiter pictures and study of the 'shoulders' and other erosion features was carried out jointly with Mr John Delano. The laboratory work on electrostatic transportation was carried out jointly with Mr Gregory J. Williams. Work on lunar studies at Cornell University is supported by NASA Grant NGL-33-010-005.

\section{References}

Gold, T.: 1955, Monthly Notices Roy. Astron. Soc. 115, 585.

Gold, T. and Soter, S.: 1970, Science 169, 1071.

Gold, T., O'Leary, B. T., and Campbell, M.: 1971, Proc. of the Second Lunar Science Conference, Geochim. Cosmochim. Acta Suppl. 2 3, 2173.

Laul, J. C., Morgan, J. W., Ganapathy, R., and Anders, E.: 1971, Proc. of the Second Lunar Science Conference, Geochim. Cosmochim. Acta Suppl. 2 2, 1139.

Muller, P. M. and Sjogren, W. L.: This volume, p. 35.

Ronca, L. B.: 1971, This volume p. 43 and Geolo. Soc. Am. Bull., June 1971.

Shoemaker, E. M., Hait, M. H., Swann, G. A., Schleicher, D. L., Schaber, G. G., Goddard, E. N., and Waters, A. C.: 1970, Geochim. Cosmochim. Acta Suppl. 1, 3, 2399.

The Lunar Sample Preliminary Examination Team: 1970, Science 167, 1325. 